\title{
An Empirical Study on Vocabulary Memorizing Method based on the Processing Level Theory in College English Vocabulary Teaching
}

\author{
Yijing Liu \\ School of Foreign Languages, Qingdao University, Qingdao 266000, China \\ 573610770@qq.com
}

\begin{abstract}
This study took 62 students majoring in new energy scientific engineering and 57 students in applied physics as the subjects, and they are two non-foreign language majors of grade 2016 students. The subjects in the experiment have received college English courses with the same teaching time and curriculum. In this paper, the vocabulary memory method based on the level of processing theory was used to carry out the teaching experiments, and these experimental subjects were respectively tested in the pre-experiment stage and experimental research stage within two months. By quantitative research methods, subjects' vocabulary memory in these two classes was tested after half a semester of teaching experiments again, and the data is analyzed by statistical software. The experimental results demonstrate that the students who use vocabulary memorizing method based on the processing level theory have better performance in vocabulary spelling and memorizing than that of the control group.
\end{abstract}

Keywords: Processing level theory, vocabulary memorizing, English teaching.

\section{Literature Review}

According to the processing level theory, English vocabulary memorizing method could be classified into shallow coding and deep coding (Zhang Qingzong and Wu Xiyan 2002, Shao ling 2006) [1,2]. Shallow level coding is a kind of memorizing method that emphasizes the for mand pronunciation of words, such as Phonics method, homophonic association, mechanical repetition and so on. Deep coding is a type of memorizing method that focuses on the features of lexical semantic, such as root affix (word-formation), contextual method, comparative association method, etc. (Lv Wenpeng, 2003, Liu Yiyuan, 2011). [3,4] Different levels of coding have different memory effects, and deep coding is more effective than shallow coding (Potter1990).

\subsection{Study on English Vocabulary Memorizing Methods in Foreign Countries}

The first step in words learning is to understand them. Dooling and Lachman (1971) [5] pointed out that contextual (contextual guessing) method could enhance learners' understanding of vocabulary. Clarke and Silberstein (1977) [6] wrote exercises to use three contextual clues (tautology, anaphora and collocation in a discourse) to help students guess the meaning of words by context. The second important task of vocabulary teaching is to remember words and, more precisely, to help students store words through memory. In any subject area, when it comes to the study of memory methods, we cannot discuss memory materials at any time. Therefore, it is beneficial to review some features of the relationship between vocabulary and memory.

Function words are few and repetitive, so they could be quickly remembered. There should be the same case with specific nouns as they have exact images. However, nouns, adverbs, and verbs that represent abstract concepts are often difficult to remember because they contain complex content; nevertheless, they are necessary to properly understand an article, and they cannot be ignored. However, they are too abstract and repetitive to be remembered (Burling1972). [7]

Root affix memory method and word family memory method are classified according to the morphology of vocabulary. The advantage of these methods is that learners could guess the meaning of new words based on their knowledge on the root meaning. By this way, when we are memorizing these words, we can reduce the burden of memory and have better memory effect. However, the words that are used to develop memories are often not common or simply limited to the professional 
use. On the basis of their meanings, words are classified by means of semantic field, synonyms and antonyms association, and metaphors. According to the Semantic Field theory proposed by the German scholar G. Trier, different words form a Semantic Field under a shared concept. Semantic Field is composed of a conceptual vocabulary and many specific words affiliated to the conceptual vocabulary. The theory of semantic field is very helpful to memorize vocabulary. Different words in the same semantic field can be learned together and some memory burden can be alleviated when memorizing them. Lakoff and Johnson (1980) [8] believed that the main way we recognized and remembered abstract things was metaphor, which enabled us to understand abstract or complex things with the help of known things. This way has a huge impact on our thinking and behavior. Obviously, metaphor is a general principle in language to organize words and phrases. The frame of metaphor can provide the associative link for us to memorize words.

In the study of memory methods, Stevik (1976) [9] believed that vocabulary was stored and remembered in the associative network. There are many kinds of associations because vocabulary was related to not only form and sound, but also to meaning. Asher (1969) proposed the total physical response method (TPR), which advocated the combination of language and behavior, taught foreign languages through body movements, and emphasized the development of abstract thinking on the basis of image thinking. Its advantage is that it can catch students' attention, attracting them to participate in activities and make them learn English in the immersive experimental experience. However, its drawback is that it is only suitable for the learners in the initial stage of language learning, and its movements and speech are mostly simple movements. It is impossible to learn profound contents by the method itself, and it must be combined with other methods.

Craik\& Lockhart (1972) [10] believed that there was a close relationship between depth of cognition and memory. They gave students a vocabulary list and proposed five problems of different depth of cognition. It was found that the deeper the task required students to know was, the more they could remember and recall was. Atkinson (1975) [11] conducted experiments on several groups of students using key words. The results showed that students using key words could recall words immediately, and the memory effect was better than that of the control group. The key word method is to link the foreign language vocabulary with its corresponding translation of native language, assisting learners' memory. This method is suitable for learning foreign languages in the same language family. For example, if the learners are native English speakers, they could learn French easily; if the learners are native Chinese learners, it will be more difficult for them to learn English by using this method of associative memory, and the method will also affect learners' pronunciation.

\subsection{Study on English Vocabulary Memorizing Methods in China}

There are more and more researches on English vocabulary memorizing methods by Chinese scholars based on foreign memory theories. As Wu Qianguang (1982) [12] said, Chinese linguists first only paid attention to the introduction of foreign memory theories and methods, and then carried out independent research on memory theories and methods. Wang Wenyu (1998) [13] conducted a survey on the memorizing vocabulary for 100 junior students, among whom50 were English majors and 50 were non-English majors. The investigation revealed that the memory method hadan impact on test scores to a large extent. Dai Manchun (2000) [14] elaborated on the benefits of using some memory strategies to acquire English vocabulary, and he suggested that strategies such as deductive method and associative method could be used in memorizing English vocabulary. Chen hui (2001) [15] found in his questionnaire that students often complained that they could not remember the words they had learned. Even if students worked hard, they always forgot the words quickly. More than 70\% of students used mechanical memory method in memory vocabulary, and only a few students used an association memory method.

Zhang Qingzong and Wu Xiyan (2002) adopted some views of lexicology and redefined the semantic processing level theory. They believed that the semantic level was not only limited to contextual meaning, but also contained the semantic network composed of the horizontal and vertical combinatorial relations of words. This study found that through the process of semantic cognition, the learning method can promote the memory effect of vocabulary. This conclusion is mainly 
reflected in that the vocabulary retention quantity and retention rate of students in the experimental group are far higher than those of the other two groups. On the level of understanding, students in the experimental group are also higher than those in the other two groups. In some ways, the processing of the form of words creates a disturbance on understanding the words. It is worth noting that they described the processing of the form to recall words pronunciation and copying the words. They described the semantic processing of words to be three stages: contextualization (original contextual meaning), non-contextualization (identifying and finding its corresponding collocation of new words), and re-contextualization (learners make sentences by themselves and restore the new words, synonyms and collocation to the original context). Lv Wenpeng (2003) applied the processing level theory to divide the memorizing vocabulary methods into two types: shallow coding and deep coding. Through the qualitative analysis of these two methods, he found the synthesis method, that is, the combination of the two coding methods, and verified in teaching experiments that this synthesis method was better than both shallow coding and deep coding. Shao ling (2006), based on level of processing theory, performed a word memorizing experiment with 60 students. She asked two groups of students (30 excellent students and 30 students with learning difficulties) to memorize three groups of words respectively at high level, medium level and low-level processing. Each group has 10 words, a total of 30 words. The students in the low-processing group were only asked to try to remember the 10 words. The students in the medium-level group were asked to use some of the letters in the given words to form a familiar vocabulary at the first step. For example, acute-eat, ample-maple, and then memorize the whole group of words. In the highly processed group, students were asked to come up with synonyms or antonyms of each word in the group, such as ample-rich and acute-quick, and then memorize the whole group of words. In the end, the experiment proved that the students' memory after a deep processing is more accurate than a low-processed memory, and the word memory of excellent students is superior to the memory of students with learning difficulties probably because the excellent students use the memory strategies of the deep level of processing in words memory.

Liu Yiyuan (2011) suggested that vocabulary teaching model based on the processing level theory mainly have four parts: the form processing, word-building processing, semantic processing and context processing. Like Lu Wenpeng (2003), he also believed that shallow coding was to memorize the morphological and phonetic features of words, such as repetition, spelling, homophony, and familiar lexical methods. Deep processing refers to semantic processing, such as root affixes, contextual method and image method, etc. He also emphasized that students should not only understand the structure, spelling and pronunciation of words but also understand the cultural connotation of words, which is conducive to enhancing words' understanding. Through researches, Li Yonghuan (2012) [16] proved that the strategy of deep association memory based on the processing level theory can improve students' vocabulary memory effect more than that of the traditional vocabulary memory method, and the strategy training can improve students' awareness of using strategies in vocabulary learning.

\section{The Experiment Design}

According to the processing level theory, English vocabulary memorizing methods can be divided into shallow coding and deep coding (Zhang Qingzong and Wu Xiyan 2002, Shao ling 2006). The shallow coding memory methods include:

(1) Phonics method. Through mastering the fixed pronunciation of consonant letters and corresponding consonant consecutive letters, and the relatively fixed pronunciation of vowel letters and vowel letter combination, students remember the words by dividing words into the syllables, so as to promote the recognition and memorization of words. As a kind of phonetic language, the pronunciation of words is closely related to its form. It is very important to grasp the correspondence between a certain number of regular letters and phrases, sounds and forms. (2) Homophonic association method, also known as analog phonetic method. Homophonic method refers to a method of using the pronunciation of Chinese characters to imitate part or all of the pronunciation of words, and then forming a sentence with the Chinese meaning of the words to help memory (Li Rubin 1991). 
For example, when you remember the word "ambulance n", it's like, "call an ambulance, I can't die!"(The Chinese meaning of I can't die is the same as that of an ambulance) (3) Using learned words. It means to remember new words by using the words you have learned (or part of the structure of the words) For example, when learning "dapple n. 斑点" and "dwarf n. 侏儒", you can use the words "apple" and "war" already learned to help you remember them (Li Xuezhi 1994).Using familiar words are simpler than root affixes because roots are usually abstract, and some roots change vowels in different words, making them difficult to understand and remember. (4) Mechanical repetition method. It refers to remember words by repeating them even without understanding them. Most students report that this method makes them forget words too quickly. Although mechanical repetition method has the worst effect (Wu Xia, Wang Qiang, 1998), it is indispensable for most students to learn vocabulary.

Deep coding memory methods include: (1) Root affixes. Use relevant knowledge to analyze roots and affixes to remember words. According to the English writer and politician Chesterfield, "the best way to learn a language is to master the root of it, the original words that have been used to form the words of the other words." (Li Pingwu 1984). In "how to improve the ability to use words", edited by reader's digest in America, the roots and affixes are compared to the keys to the lexicon learning. This shows the importance role root affixes play in lexicon learning

(2) Context. It means to remember words by the use of context or reading between the lines. In the context, students can not only learn the conceptual meaning of vocabulary, but also learn pragmatic meaning or metaphor. Studies by Wu Xia and Wang Qiang (1998) have shown that the context method is the most effective one to memorize words. Ahmad (1989) believed that the higher the level of a foreign language was, the more it would be to benefit from the context method. (3) Contrast association. We should memorize the words together when they have morphological, phonetic, Spatio-temporal or logical relations in the same pronunciation but different meanings, the same form but different pronunciation and different meanings, synonyms, antonyms, the same semantic field, and the upper and lower semantic fields. (Liu Zhongjun 1998, Zhou Ronghui 2003, Liu Yuxiu 2004).

\subsection{Design of Experimental Conditions}

Based on the processing level theory, the students in the experiment are asked to memorize the vocabulary by different processing methods. Students in experimental group 1 memorized words by repeating and copying, and students in experimental group 2 memorized words by semantic processing. The experimental results verify that semantic cognitive processing has significant influence on the word memory in short time and in long time.

The subjects in the experiment are two majors of non-foreign language major's students in 2016, and they respectively major in new energy science and engineering (62 students) and applied physics (57 students). All of the students in the experiment have received college English courses with the same teaching time and courses category, and they also have taken CET4.

In the experiment, the students majoring in new energy science and engineering, are in experimental group 1, and the students majoring in applied physics are in experimental group 2. Before the experiment began, the students in both groups participated in the experimental testing phase, in which they were asked to read textbooks to test their ability to acquire information. According to the analysis of variance, there was no significant difference in vocabulary level between the two experimental groups. Then, the experimental subjects in the two groups would use different methods to learn and memorize vocabulary in experimental teaching phase.

In this experiment, unit 1 and unit 2 of volume 3 of the third edition of college English edited by Zhejiang University were adopted. There were four texts in total, followed by a list of defining words, all of which were in the text. Since there is no context for the word list, the words can be directly recited and copied to remember. However, they all appear in the text with context, so this textbook meets the experimental requirements.

50 words were selected from each unit for the subjects to memorize. The selecting criteriao fare the vocabulary required by cet- 4 and cet- 6 , and the vocabulary with multiple synonyms and phrase 
collocation that can form semantic network. Therefore, this kind of words could not only arouse students' activity, but also facilitate them to semantically process the words.

Test questions are divided into writing English words from memory and making Chinese-English multiple-choice. In the experimental test, the English words were written from memory, that is, the students were asked to write some selected English words with their Chinese meaning according to their own memory, so as to test their memory effects. Choosing questions in both Chinese and English is to give the English words in the question stem and choose the correct Chinese meaning in the four choices.

\subsection{Experimental Stage}

This experiment is a tree-like diagram, divided into two one-level stages and four two-level stages. The first stage is the pre-experiment testing stage and experimental research stage respectively. Each stage consists of two levels of memory and testing.

In the pre-experiment testing stage, both subjects in the two groups are to learn the text of unit 1 to assist understanding and memorizing words in the unit. In other words, the structure of the text and the main idea of the paragraph are discussed during the class. At the same time, the subjects only focus on learning the sentences that contain the target vocabulary, by translating and understanding, no need to remember the words deliberately. At the end of the learning stage, that is, the test stage, the subjects were tested that how many target words they had memorized. After analysis, the test results showed that subjects in the two majors had similar performance in mastery of vocabulary.

In the experimental stage, the students learned vocabulary of unit 2during the learning phase. The subjects of the first group mainly adopted the method of repetitive memory and writing by using word list. They repetitively read the words by continually correcting their pronunciation to memorize vocabulary, as well as, by copying and dictating words. The subjects of the second group carried out semantic processing while learning vocabulary. The first step was to put the target words into the original text to understand their meaning and usage. The second step was to solely learn and memorize the words by separating the target words from the original sentences. The third step was to put the target words into the new related context which created by themselves to memorize and apply the words again.

The experimental research is divided into the instant test and the maintenance test. The instant test means a direct 15-minutes test after learning. The maintenance test is to carry out after the learning class is closed for four weeks. When the instant test is closed, the teachers immediately collected the test papers and other learned contents so that students can't memorize the test content. The two tests have the same content and testing time.

\subsection{Data Analysis}

In this experiment, the students were tested three times. That is to say, the test before experiment, the instant test and the maintenance test. In the first test, subjects were tested to guarantee they were all qualified by testing whether they have similar understanding for the target words. The instant test tested how well the subjects remembered the words through different processing methods before forgetting them. The maintenance test tested subjects' retention of the leaned words four weeks later.

\subsubsection{Pre-experiment Testing Stage}

In order to test the acceptability and comprehension ability of the students in the two groups in English teaching, we carried out an experimental test and conducted equal variance test on the test results. 


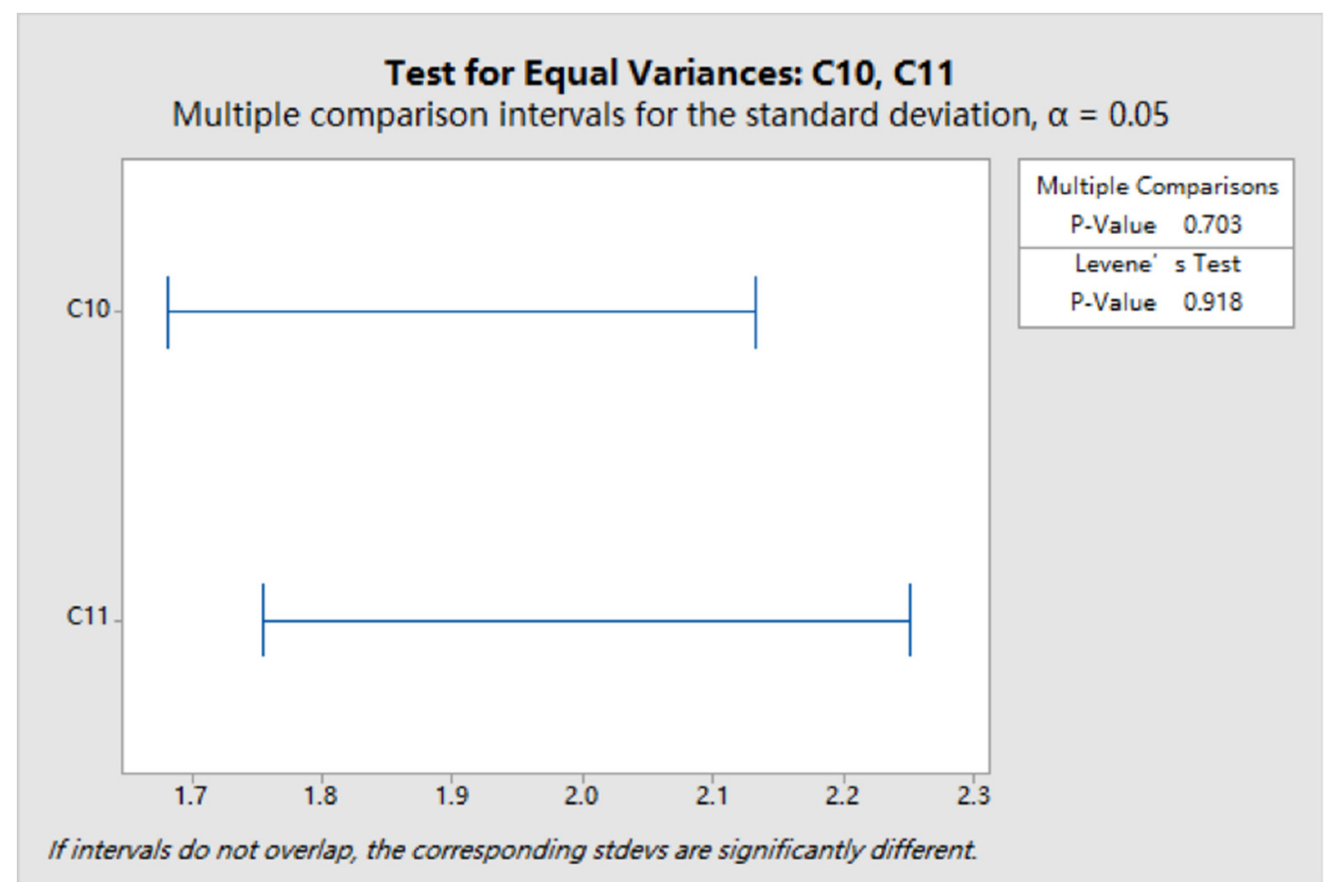

Figure 1. Test for Equal Variances:C10, C11

As shown in the figure, as the variance of subjects of the two groups is not known, Liven Test is used to judge their variance level. For subjects in the two groups, the level of variance represents their internal differences, that is, the difference of strengths and weaknesses. Significance level is set to be 0.05 . In the results analysis, $\mathrm{C} 10$ represents the variance level of the first group and $\mathrm{C} 11$ represents the variance level of the second group. What the Liven Test results show is that p-value is 0.918 , which means that the difference between the two groups is relatively small, that is, all students are at the same level, and those with high scores are at the same level as those with low scores. There will not be any group of students whose English are at a high level, and there will not be any group of students whose English are at a low level.

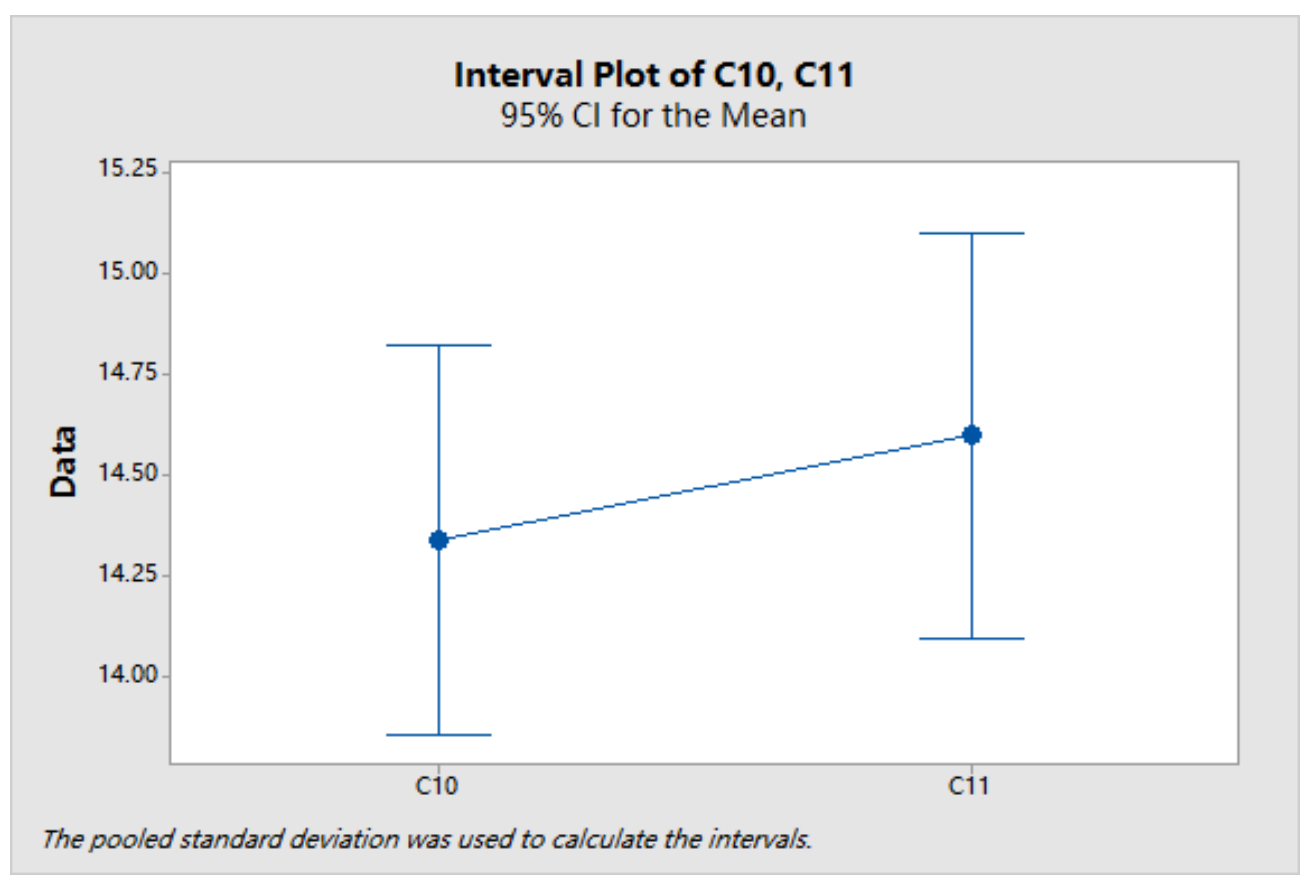

Figure 2. Interval Plot of C10, C11. 


\begin{tabular}{|c|c|c|c|c|}
\hline Factors & Number & $\begin{array}{c}\text { average } \\
\text { value }\end{array}$ & $\begin{array}{c}\text { standard } \\
\text { deviation }\end{array}$ & $\begin{array}{c}\text { Expectation upper and lower bounds under } \\
95 \% \text { confidence }\end{array}$ \\
\hline $\begin{array}{c}\text { Group } \\
1\end{array}$ & 62 & 14.339 & 1.864 & $(13.859,14.818)$ \\
\hline $\begin{array}{c}\text { Group } \\
2\end{array}$ & 57 & 14.596 & 1.954 & $(14.096,15.097)$ \\
\hline
\end{tabular}

As shown in the above table, although there was a certain difference in the scores of the two groups, the average score of 14.596 of the students in the second group was still within the upper and lower bounds of the expectation of the students in the first group under the confidence level of $95 \%$, which could be assumed that the English level of the student sin the two groups are at the same level.

\subsubsection{Experimental Test}

(1) Instant test completion

(2)

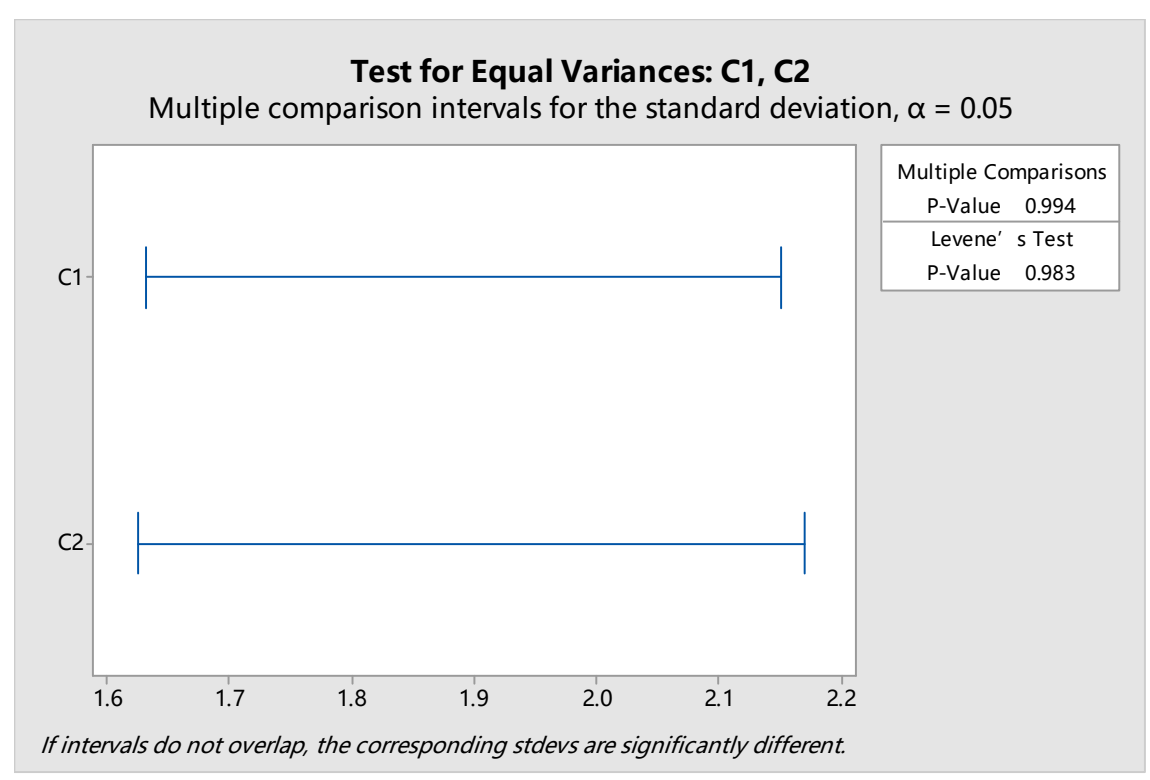

Figure 3. Test for Equal Variances:C1, C2.

As shown in the figure, Levin inspection showed that subjects in the two groups could be assumed to obey the same variance, so the subsequent ANOVA was effective.

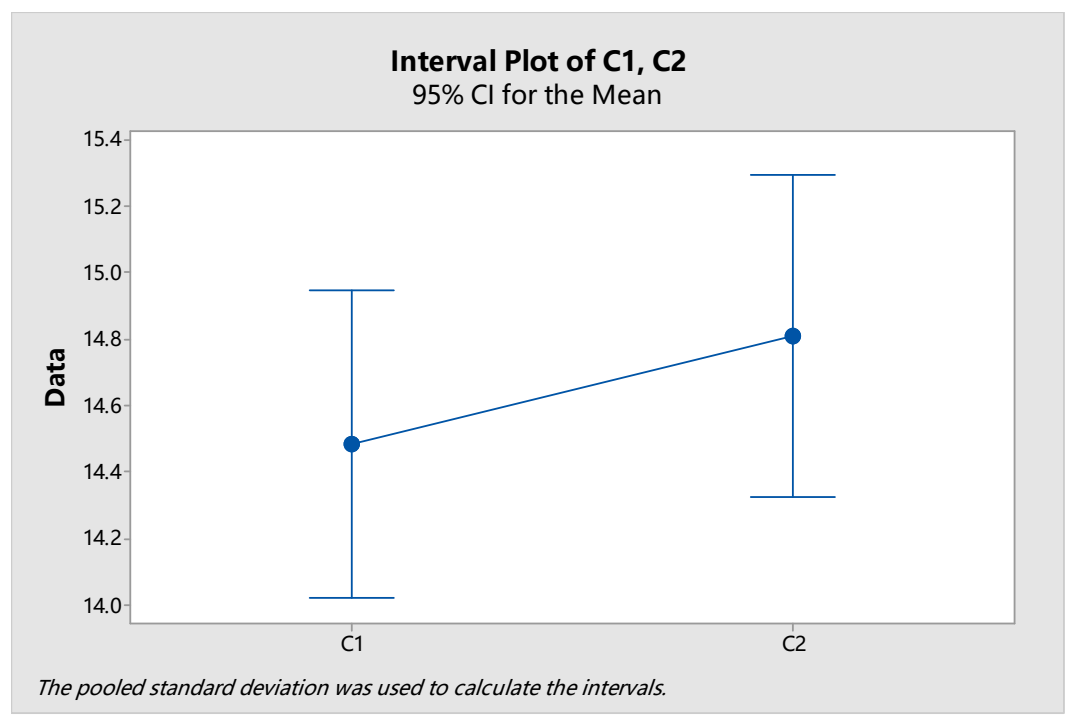

Figure 4. Interval Plot of: C1, C2. 


\begin{tabular}{|c|c|c|c|c|}
\hline Factors & Number & $\begin{array}{c}\text { Average } \\
\text { value }\end{array}$ & $\begin{array}{c}\text { Standard } \\
\text { deviation }\end{array}$ & $\begin{array}{c}\text { Expectation upper and lower bounds under } \\
95 \% \text { confidence }\end{array}$ \\
\hline $\begin{array}{c}\text { Group } \\
1\end{array}$ & 62 & 14.484 & 1.844 & $(14.020,14.948)$ \\
\hline $\begin{array}{c}\text { Group } \\
2\end{array}$ & 57 & 14.807 & 1.846 & $(14.323,15.291)$ \\
\hline
\end{tabular}

As shown in the table, although there was a certain difference in scores between the two groups, but the average score of 14.807 in the second group was still within the upper and lower bounds of the expectation of the first group under the confidence level of $95 \%$, which means that the two groups of students are at the same level. From the figure and table, it is shown that the students in the two groups performed equally in the test of filling in the blank in the instant test, that is, different teaching methods did not show significant differences in teaching effect in the test of filling in the blank in the instant test.

(3) Instant test

Multiple choice of instant test

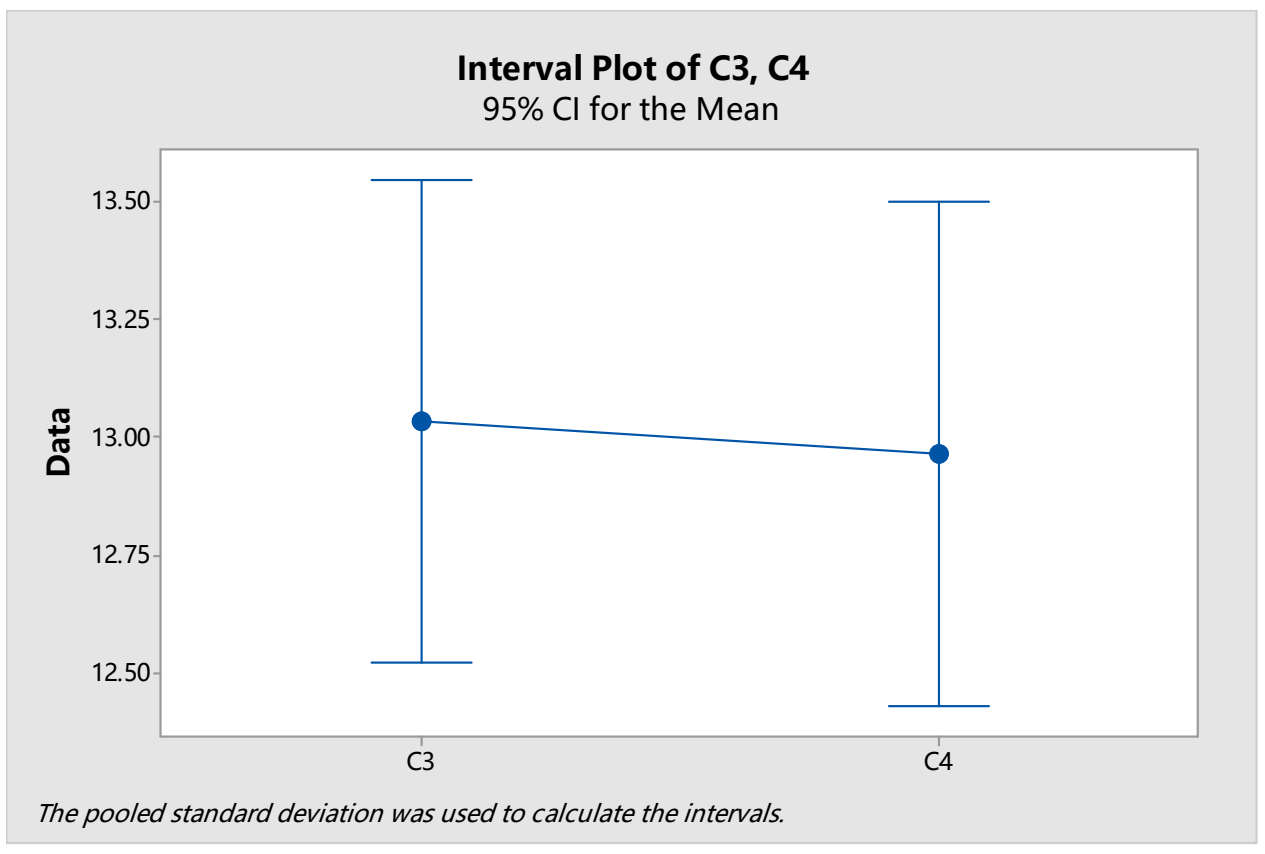

Figure 5. Interval Plot of: C3, C4.

\begin{tabular}{|c|c|c|c|c|}
\hline factors & number & $\begin{array}{c}\text { Average } \\
\text { value }\end{array}$ & $\begin{array}{c}\text { Standard } \\
\text { deviation }\end{array}$ & $\begin{array}{c}\text { Expectation upper and lower bounds under } \\
95 \% \text { confidence }\end{array}$ \\
\hline $\begin{array}{c}\text { Group } \\
1\end{array}$ & 62 & 13.032 & 2.016 & $(12.520,13.545)$ \\
\hline $\begin{array}{c}\text { Group } \\
2\end{array}$ & 57 & 12.965 & 2.061 & $(12.430,13.499)$ \\
\hline
\end{tabular}

As shown in the table, although there was a certain difference in the scores of the two groups, the average score of 12.965 of the students in the second group was still within the upper and lower bounds of the expectation of students in the first group under the confidence level of 95\%, which could be assumed that the English level of the students in the two groups are at the same level.

As shown in the Figure 1 above, there was no significant difference between the two groups in the test of instant test multiple choices. 
From these above analyses, the form processing teaching method and semantic processing teaching method have no differences in words memory in instant test. However, the degree of processing level has influence on words memory in short term memory.

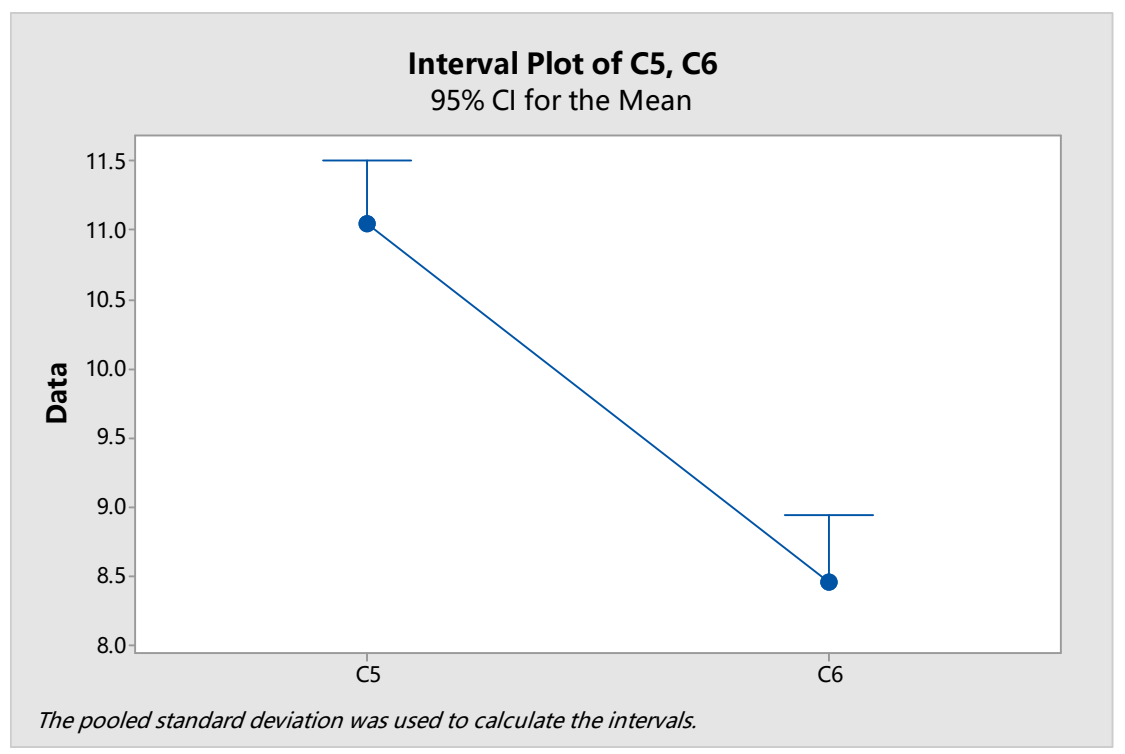

Figure 6. Interval Plot of: C5, C6.

\begin{tabular}{|c|c|c|c|c|}
\hline factors & Number & $\begin{array}{c}\text { Average } \\
\text { value }\end{array}$ & $\begin{array}{c}\text { Standard } \\
\text { deviation }\end{array}$ & $\begin{array}{c}\text { Expectation upper and lower } \\
\text { bounds under 95\% confidence }\end{array}$ \\
\hline C5 & 62 & 11.048 & 2.199 & 11.509 \\
\hline C6 & 57 & 8.456 & 2.172 & 8.936 \\
\hline
\end{tabular}

(4) Filling in the blanks in Maintenance test

Multiple choice of instant test

As shown in the above figure and table, with the $95 \%$ confidence level, the results of subjects in the first group were significantly higher than upper bound of the expectation of the second group of 8.936 , that is, it is $95 \%$ confidently believed that there was a significant difference between the scores of the two groups. The students in group 1 have significantly better performance than the ones in group 2 in words memory.

Multiple choice of maintenance test

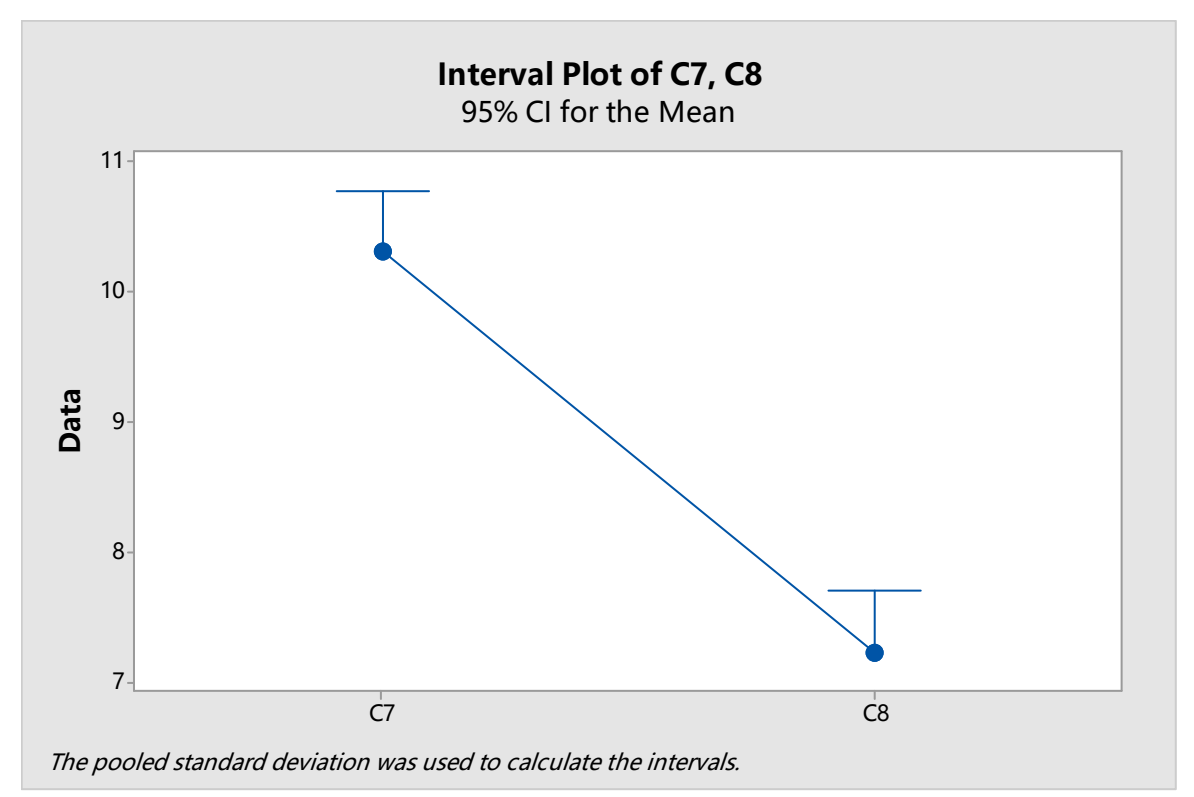

Figure 7. Interval Plot of: C7, C8. 


\begin{tabular}{|c|c|c|c|c|}
\hline factors & number & $\begin{array}{c}\text { Average } \\
\text { value }\end{array}$ & $\begin{array}{c}\text { Standard } \\
\text { deviation }\end{array}$ & $\begin{array}{c}\text { Expectation upper and lower bounds under } \\
95 \% \text { confidence }\end{array}$ \\
\hline C7 & 62 & 10.306 & 2.132 & 10.757 \\
\hline C8 & 57 & 7.228 & 2.147 & 7.698 \\
\hline
\end{tabular}

As shown in the figure and table, the results of the first group were significantly higher than the upper bound of the expectation of $95 \%$ confidence of the second group, which was 7.698, which means there was a $95 \%$ confidence that there was a significant difference in scores between the two groups.

As shown in the figure and table above, the subjects in the two groups showed significant differences in multiple choices in the retentive test, and the memory degree of vocabulary in the group 1 was significantly better than that in the group 2 .

It can be obtained from the data analysis of the retentive test that he different processing methods to keep the memory of vocabulary have bigger difference, which means the memorizing retention of form processing is inferior to that of semantic processing. The students in experimental group 1 take shallow processing, which also called form processing, and their memorizing level was worse than that of deep processing method of semantic understanding and contextual feeling.

\section{Analysis of Conclusion}

(1) The words memory method based on the processing level theory improves students' memory in certain degree. In the vocabulary test, which is before the start of the teaching experiment, the results of the first group were significantly higher than the upper bound of the $95 \%$ confidence expectation of the second group (8.936). At the same time, the overall average score of the second group was significantly better than that of the first group, which in dicates that the improvement of the memorizing vocabulary of the second group was significantly better than that of the first group. Therefore, in this process, the introduction of teachers and new vocabulary memorizing methods has become the key reason for the significant changes in scores of the two classes. Since the same teacher is in charge of the first group and the second group, the introduction of new vocabulary memorizing methods has become the single important factor affecting the improvement of the experimental class's vocabulary memorizing ability. Therefore, it is concluded that the words memorizing method based on the processing level theory can improve the correct words spelling, increase the number of words grasped its Chinese meanings and help students to remember new words more easily and effectively.

(2) In the pre-test and post-test, the distribution of individual scores expanded. Before the start of the experiment, the first group had the same performance with the second. But after the experiment, the standard deviation of the second group was greater than the standard deviation of the first group, which indicated that the individual score difference of the second group was greater than that of the first group. Considering that the average score of the second group was improved in the first and second tests, it can be seen that through this experiment, most of the students who could understand the memorizing method would greatly improve their scores, while those who could not understand and use the method would get worse scores.

(3) The subjects in this study were 62 students majoring in new energy scientific engineering and57 students majoring in applied physics, and they were two majors of non-foreign language majors in 2016. These subjects had received college English courses of the same teaching time and setting course, and they had also taken CET4. The purpose of this paper is to test whether this method has any effect on the vocabulary learning for junior middle school students. Through the data analysis and discussion of the experimental research, the following conclusions are drawn: integrating the word memorization method based on the processing level theory into students' daily vocabulary learning is a kind of learning method based on spelling knowledge that aims at memorizing words to enable students to effectively memorize words. If teachers want to apply the opposite in daily teaching, they will need to prepare rich spell exercising materials, students then are asked to practice, observe and summarize more. They are instructed not to deviate from the key points in the learning process. 
They are also instructed to demonstrate their associative ability in memorizing new words, making known and unknown connections to remember words better. These undoubtedly add more requirements and contents to teachers' preparing work, but it also conforms to the goal of "teacherguided -- student independent learning". From the results of this paper, this method can also improve students' learning effect and interest, which are two contradictory aspects for students' learning. It is not reasonable to avoid difficulties to only talk about interests as well as, avoid interests to only talk difficulties. Without difficulties and challenges, students will not have any interest in learning. If the difficulties in learning process are not overcome, the students' rising interest in learning will not last long. Thereby, the teachers should pay attention to the difficulties in students' learning, finding solutions and overcoming difficulties in time, which will continually enhance students' confidence and interest in learning process.

\section{References}

[1]. Zhang Qingzong,Wu Xiyan. Depths of Processing and L2Vocabulary Learning[J]. Modern Foreign Languages (Quarterly), 2002, (2):176-186.

[2]. Shao Ling.Experimental study on the relationship between the level of processing and awareness in vocabulary memory [J].Contemporary education BBS,2006, (6):116-117.

[3]. Lv Wenpeng. The application of processing level theory in the study of lexical memory [J]. Journal of xi 'an international studies university,2003, (1) :48-50.

[4]. Liu Yiyuan. English vocabulary learning theory -- level of cognitive processing theory [J]. Learning theory,2011, (8)169-170.

[5]. Dooling, D. J.\& Lachman, R. Effects of comprehension on retention of prose[J]. Journal of Experimental Psychology,1971(88): 216-222.

[6]. Clarke, M \& Silberstein, S. Toward a realization of psycholinguistic principles for the ESL reading classroom[J]. Language Learning,1977,27(1):135-154.

[7]. Burling, Robbins. Sounding Right[M]. Rowley, Massachusetts: Newbury House Publishers, 1982.

[8]. Lakoff, G.\&M. Johnson. Metaphors We Live By[M]. Chicago: Chicago University Press, 1980.

[9]. Stevick. E.W. Memory: Meaning and Method[M]. Rowley, Mass: Newburg House, 1976.

[10]. Craik, F. I. M.\&R. S. Lockhart. Levels of processing: A Framework for Memory Research[J]. Journal of Tlerbal Learning and Tlerbal Behavior 11,1972.

[11]. Atkinson \& Shiffrin. The Model of Human Memory[M]. United Kingdom: Cambridge University Press,1968.15-24.

[12]. Wu Qianguang. Talk about how to learn English vocabulary [J]. Modern Foreign Language,1982, (3): 53-58. 